\title{
The Contested Rise of a Modernist Technology Politics
}

\author{
Johan Schot
}

This chapter explores the idea that as part of a modernization process that gained speed in the nineteenth and twentieth century in the western world, a typical modernist practice of technology politics emerged. ${ }^{1}$ The concepts of modernization and modernity need to be handled with care, of course, since their use may easily lead to an identification with modernizers, actors who have invented and used these labels to advance their cause. In addition, using these concepts for analysis might lead to finalism, as if past developments have led right up to the present. When these two pitfalls are avoided, the concepts of modernization and modernity are useful categories to discuss various structural changes in western societies since the eighteenth century. The concept of modernization refers to a new mode of social organization, a new social order, and a discontinuity in history (Wehler 1975; Giddens 1990). It is best understood as a process associated with a specific time period (eighteenth century to the twentieth century) and geographical location (the western world). The concept of modernity furthermore refers to a specific mode of thinking in which technology is identified as the main way of advancing the modernization process. Technology has been far more central to the making of modernity than is usually recognized (Brey, chapter 2, this volume; Hård and Jamison 1998; Latour 1993).

The modernist politics that slowly emerged consists of separating the promotion of technology from the regulation of technology. In this practice, technology development is perceived as a neutral, value-free process that needs to be protected and nurtured (because it creates progress, material wealth, health, etc.). Special "free places," often called laboratories, are created where engineers, inventors, and other 
technology developers can focus on solving technical problems. If these problems are solved, technologies begin their journey to the "real world." Fitting technologies into a market is the business of entrepreneurs (innovators).

Sometimes, as the modernist politics recognizes, these technologies will have undesirable impacts for society. To help societies deal with these impacts, government or other bodies put into place regulations to protect and if necessary compensate citizens. These undesirable impacts, in the modernist view, are unrelated to the choice of a technology. The modernist view does not recognize an important feature of technical change, the co-production of technology and its effects. The social effects of any technology depend crucially on the way impacts are actively sought or avoided by the actors involved in its development. In the modernist view, impacts are perceived as acceptance problems. Hence, technology promoters devote substantial resources to persuading the public to adopt a "better understanding" of the issues at stake. Technology promoters do test their innovations and if necessary modify them to fit with the regulatory system and the worldviews of the public. However, the modernist style of regulation does not require technology developers to consider impacts and "impact" constituencies systematically, let alone at an early stage, while technologies are undergoing development and taking on their durable forms. The emergence of this modernist technology politics went hand in hand with the development of a dichotomized discourse on technology. Reinforcing the modernist practice of promoting and regulating new technologies was the emergence of two dominant perspectives: an instrumental one in which technology is a neutral means toward an end, to be defined outside the technical area and, by contrast, a strong critique asking for (regulatory) limitations on technical action. ${ }^{2}$

This essay first explores the rise of this modernist technology politics, spotlighting key turning points from the early nineteenth to the midtwentieth centuries, and then suggests ways to go beyond such a dichotomous politics. My ultimate aim is to identify ways to open up space for the actual shaping of technology and for discourses on how to manage technology in society. In my discussion of the rise of the modernist technology politics, I particularly focus on episodes of resistance 
to technology. There are both substantial and methodological reasons for doing so. The emergence of the modernist regime of technology management was highly contested and it is important to make this contested process visible, particularly because the notion of modernization can easily lead the author (and reader) to the pitfall of finalism and the writing of whiggish history. Resistance is also interesting for methodological reasons because various kinds of positions can be more easily found in source material.

This essay is an attempt to construct a plausible account of a modernist regime of technology management. It is a broad-ranging and interpretative attempt to bring together diverse material to form a meaningful and coherent story. It can also be read as an attempt to bring together my background in social history, sociology of technology, and policy studies, together with my practical experience in several technology-policy networks. ${ }^{3}$ It draws on systematic reflections resulting from circulating in various networks and disciplines. The argument is, therefore, speculative, but a starting point for further research and discussion on the relation between modernity and technology.

\section{Politics and Innovation in Early Modern Europe}

In the early modern period, a distinct technological domain did not exist. Technological development was embedded in religious, economic, and social practices, and it was assessed against social norms. The assessment processes, which were often informal, took place in guilds, for example. While guilds often slowed down specific innovations, they were not against all forms of technological development; they hindered only those technologies that were contrary to their ideas about the "good society," for example, machines that would threaten skill or employment. Technological development was heavily influenced by the regulatory (and evaluative) practices of guilds (Mokyr 1990: pp. 258-289). It was also shaped by a variety of protests, such as organized demonstrations, petitions, threats to inventors and entrepreneurs, and breaking machines (Rule 1986).

The destruction of machines is associated with the acts of the Luddites, the English workers who destroyed textile machines in the early 
nineteenth century. ${ }^{4}$ For decades, the Luddites were held up as irresponsible if unwitting technophobes. Historians once viewed them as the victims of progress, who saw no other recourse than taking out their aggression on the machine. Often, it was added, every new technology is resisted because of vested interests, but that resistance eventually subsides. Hobsbawm (1952), Thompson (1963), Rule (1986), and Randall (1991) have corrected this mistaken image of the Luddites. According to their research, organized machine breaking had been a rather popular and successful form of protest since the seventeenth century. It was more effective than striking because employers could not employ scabs to keep the machines in operation. Hobsbawm called it "collective bargaining by riot." In saving the Luddites from modernistic criticisms, these revisionist historians have sometimes argued that the Luddites' protests were not directed against technical change or machines. I would like to argue, however, that their protest did entail a strong criticism of technology. Their critical stance was not based, however, on disdain for technology in general. On the contrary, it was directed at particular machines. The only machines the Luddites destroyed were the ones against which the workers had particular grievances. Other machines, even in the same factory, were left unscathed. A crucial point that is often lost in the popular image of the Luddites as an uninformed antimachine mob is that most Luddites were skilled machine operators in their own shops.

Moreover, I would like to emphasize that the Luddites' resistance ran much deeper than the rejection of particular machines. It concerned the rise of a new kind of society, embodied in a new set of specific machines, in which employers had the right to introduce machines that made workers redundant, produced unemployment, and lowered the quality of the products and the quality of society. Randall, who carefully analyzed the discourses used by various workers, argues, rightfully, that the workers were not just trying to restore an old situation (Randall 1991). Rather, they acted proactively to develop their own view of the future, a future that in their time was a genuine and feasible alternative. It was a struggle between rival models of how to organize society. The Luddites demanded that those who introduced new machines should anticipate their social effects. One of the Luddites' proposals was a machine tax intended to create fair competition between the power loom and the hand 
loom (see Berg 1980). In other cases, workers asked for a negotiated introduction of machinery. They proposed an experimental period to assess social costs and social benefits (Randall 1991: pp. 72-74). Some evidence exists that attempts were made to construct "intermediate" machines, which would need more hands and skills; in addition, certain machines were available for small-scale domestic manufacture. Two such cases from the cotton textile sector, which would benefit from economies of scale, are James Hargreaves's “jenny” and Richard Arkwright's water frame, which was deployed on a large factory scale because of patent-law considerations even though it had been developed initially for small-scale domestic use. ${ }^{5}$

To the employers and entrepreneurs, as well as the politically dominant classes in Britain, the Luddites were criminals. Labeling machine breaking a criminal act was, however, part of the struggle of developing a specific kind of industrial society. Initially the Luddites had English law on their side, for machine breaking as a form of protest was legitimated by the common law. Only in 1769 did the Parliament pass a new law against machine breaking. Luddites were not alone in their dissent. They were supported by craftsmen, small-time entrepreneurs, and conservative politicians (Randall 1991), the last of whom were strongly influenced by early Romantic authors such as Carlyle and Southey (Berg 1980: chap. 11). Finally, Luddite resistance must be seen against the background of the national debate on the "machinery question." This debate centered on the sources of technical progress and the impact of new technologies on the economy and society. It spurred the development of a new discipline, political economy (Berg 1980).

The Luddites lost their battle in the end, partly as a result of strong state intervention. During a wave of protests in 1811-13, some 12,000 soldiers-a force much larger than Wellington's army then fighting Napoleon at Waterloo-were sent against the workers to "restore order" in the textile regions of England. While the Luddite movement was destroyed, it can be argued that it slowed the introduction of a number of machines, particularly in the woolen industry, and the threshing machine in agriculture (through the so-called Swing riots). In this way the workers bought time to adjust to the changes. ${ }^{6}$ However, the main outcome was the emergence of a new ideology and practice 
that granted inventors and entrepreneurs near-complete freedom to introduce new machines into society without having to think about their effects.

The replacement of the early-modern order by a new industrial order, including a new relationship between politics and technology, was an integral part of industrialization in many western European countries. Ken Alder has argued that in France during the French Revolution engineers pioneered and founded new institutional structures to control and discipline the productive order (Alder 1997, see especially the introduction and chap. 8; for the French case see also Rosenband $2000^{7}$ ). The French Revolution was not initiated in the name of the factory, but it was supported by engineers seeking to create institutional forms to regulate production, especially to enforce forms of industrial and factory production. As in the case of England, these attempts met fierce resistance from labor and petty commodity producers. For example, in Saint-Etienne in 1789 a crowd of armorers, with the municipality's consent, destroyed a factory that aimed at mechanized barrel forging with trip-hammers (Alder 1997: pp. 214-215). When the Revolution turned violent, engineers, to keep their heads attached to their bodies, learned to position themselves as neutral, not involved in politics. ${ }^{8}$ (Historians largely accepted this view in subsequent decades, obscuring the relationship between the industrial and political revolutions in France.) This neutral position led to the development of a new strategy, one in which engineers became licensed experts of the state responsible for controlling the productive order.

In many European countries persistent resistance to new technologies became obsolete, condemned, and perceived as reactionary. Romantic thinkers, who had struggled to construct a political vision that allowed innovation while protecting society against some of the impacts of new machinery, made a utopian turn after the French Revolution and the dreadful experience of the English industrialization (Sieferle 1984). The machinery question was "solved" through the gradual acceptance of the instrumental vision by all parties during the course of the nineteenth century. Leading spokesmen of all major political parties and most interest groups agreed on a consensus in which technological innovation was acclaimed as a progressive force. Even radical reformers (such as 
Owen), and later Marxists and socialists, came to share this instrumental vision. These radicals argued that social problems must not be associated with the machine itself, but with the machine's use in a capitalist context. Owenites argued, for example, that machinery used in a cooperative social context would benefit labor since the productivity gains following mechanization could be redistributed to the working class (Berg 1980: p. 270). ${ }^{9}$ By the end of the nineteenth century, modernist technology politics was firmly in place. The elite (the right wing as well as the left wing, employers as well as unions and intellectuals) almost automatically condemned resistance to new technology as reactionary.

\section{Testing and Celebrating Modernization}

One of the few violent outbursts of resistance to the machine in the early twentieth century took place in the Netherlands. In 1905 grain elevators (unloaders) were introduced at Rotterdam harbor. These elevators were large suction devices that conveyed grain from one ship to another almost without human intervention. Thousands of dockworkers, who had worked carrying sacks of grain, were to lose their jobs. When the first grain ships were unloaded, the automatic weighing did not work; its indications were too high. In the 6 weeks it took to repair this, the dockworkers organized themselves. When the unloaders were ready to start working again, they called a strike. This strike was a great success, blocking almost the entire grain transshipment. When the German grain importers heard about the strike, they negotiated a contract with the labor leaders and the factors, the importers' local representatives in the harbor, to accept only grain that had been weighed by hand. As a result, the unloader company could not find enough work for their two unloaders. For two years the elevators remained dormant.

In 1907 the unloader company began once again unloading grain ships with the elevators, provoking another strike, but this time the workers, with their strike funds depleted, could not win. The employers, including the factors, had united and had recruited strikebreaking scabs from all over the Netherlands and from Germany. Rotterdam's mayor proclaimed a state of siege; warships appeared in the harbor; and military troops were called out to preserve order. More elevators were 
introduced and many jobs were lost. By 1912 sixteen unloaders were on duty, handling 90 percent of the harbor's flow of grain. ${ }^{10}$

In this pitched conflict, conducted not only by striking workers but also in a wide public debate, it is curious that the obvious technology choices involved in elevator design did not come under discussion. ${ }^{11}$ Union and socialist leaders embraced the new technology and argued it would bring progress to the harbor. Machine breaking, condemned as Luddism, was not on the agenda. The union and socialist leaders endlessly repeated the message, familiar from Marx and Owen, that any problems were not due to technology but to its uses under capitalism. In the new socialist society, the tremendous productive forces built up under capitalism would be employed for the benefit of all: "our watchword should not be 'away with machinery' but 'away with the capitalists and capital to the workers" " (see van Lente 1998a: pp. 93-94). One prominent socialist leader even argued that losing strikes against new machinery was in the best interest of the working classes.

Representatives of the broad-based anarchist movement, probably representing a larger part of the laborers, however, denounced the technological determinism implied in the views of the union and socialist leaders. Much like the Luddites a century before in England, the anarchist movement viewed the harbor as a community in which the employers had no right to impose, without negotiation, a machine that would deprive hundreds of workers of their daily bread. They also denied the economic necessity of the unloaders, without rejecting laborsaving machinery in general. Research in the minutes of the meetings of grain traders has proven that this view was, remarkably enough, shared initially by a number of grain traders and employers (see van Driel and Schot 2001). However, when the conflict hardened, the grain traders redefined the conflict into one about who controls the harbor and the introduction of new machinery, and closed ranks with those arguing for the economic necessity of elevators.

The consensus among the Dutch elite and part of the labor force on the instrumental role of technology in society was certainly challenged by labor in the elevator conflict during 1905-7. Yet the instrumental view emerged stronger than ever. In this period, the instrumental vision was also challenged in different ways in a number of European countries 
and the United States (Hård and Jamison 1998). After 1870 in a number of European countries it was impossible to ignore some of the problems associated with the introduction of new machines, such as bad hygiene in cities, child labor, and accidents involving machinery. "New liberals" started to write extensively about the social consequences of industrialization. They argued that these problems should not be attributed to industrialization itself, but to human ignorance and immorality, obsolete institutions, and outmoded laws. Social legislation could solve these problems. These issues were part of the "social question," which would dominate discussions.

In Germany the social question took the form of a machinery question, partly as a result of the dreadful experience of World War I. In Germany, one had to come to grips with wartime chaos and postwar depression. Technology became a much-debated issue (see Hård 1998; Dierkes et al. 1990; Herf 1984). To summarize, technology was seen as important for creating order and control, but only in a modified form. Technical change needed organization and control and regulation by the state, and the creation of domestic monopolies to guide its implementation. For example, Sombart argued that the government must appoint a body to decide what new inventions should be developed. He also argued that the police must prohibit the use of technologies with negative consequences for citizens and workers. He approved the decision of the Swiss canton of Graubünden to ban the use of automobiles and motorcycles (Hård 1998: p. 62). These modifications would make technology part of the German Kultur. Whereas U.S. technology was part of corrupt western Zivilisation, German appropriation would transform technology into an order-bringing and Kultur-enhancing mechanism. A number of influential authors (Schweitzer, Sombart, Rathenau, and Spengler) argued, in various ways, for a German Sonderweg (loosely, “alternative path") in technical change.

Generally, participants in the German debates considered modernization to be desirable, but thought that its consequences should be controlled and regulated, either by engineers or sociologists. Modernization could thus become controlled modernization. In the debates, it is clear that for Sombart and others, technology was not an autonomous realm of society; it could be shaped and fitted into the German context. 
Sombart used the notion of "cultural carpet" to analyze the relationship between technology and other spheres of society, suggesting that Germany could develop its own style and combination of technology and society (Hård 1998: p. 58).

Even though some figures proposed a new kind of technology politics (Dessauer 1958) that would exert more control over technology, the outcome of the German debates reconfirmed the modernistic technology politics: state intervention might accommodate the embedding of technologies in society (for example, with safety regulations), but there could be no direct intervention in the innovation process itself. Even Sombart eventually accepted the instrumental view. He argued in 1934 that "technology is always culturally neutral and morally indifferent; it may serve either the good or the bad," a definition that, rather jarringly, does not fit his earlier use of the notion of cultural carpet (Hård 1998: p. 63). ${ }^{12}$

A wave of technological enthusiasm in the early twentieth century stiffened the modernistic consensus about the apolitical role of technology in society. People started to refer to "technology" in the singularan independent and abstract phenomenon that transcended its many individual fields of application (Marx 1994; Oldenziel 1999). Technology became the very symbol of modern society. The belief in the technical fix, in shaping a new society by means of modern technology, assumed unprecedented proportions. Social and cultural advances through technology appeared limitless. This belief became visible in several technocratic movements in many western European countries and the United States. Their objective was to promote the prosperity of the people, through the use and implementation of technology. In art and architecture, the new belief in technology led to the emergence of new movements, such as Futurism and De Stijl. These movements celebrated the coming of the machine as a new joyful age. Theo van Doesburg, one of the leading figures in De Stijl, heralded the new age as follows:

You long for wildernesses and fairy tales? I will show you the order of engine rooms and the fairy tale of modern production methods. Each product is a real miracle. You long for heaven? I will show you the ascension of the aeroplane with its quiet pilot. You long for nature? Her dead body is at your feet. You have beaten her yourself. Your high mountains have changed into skyscrapers. Your windmill is no longer turning - a chimney has taken its place. Across the 
place once occupied by your stage-coach, now an automobile is zooming along. (Quoted in Anbeek 1994: p. 123)

Technological enthusiasm was pervasive in this period (Hughes 1989: chap. 7). This enthusiasm was not only widespread among the elite of engineers, scientists, architects, and artists, but also in the world of business, social organizations, and among citizens. The enthusiasm was embodied most clearly at the New York World's Fair of 1939, which presented "The World of Tomorrow" (see Nye 1990: pp. 368-379). In this world technology was presented as the key instrument of a better society. The fair was explicitly and consciously concerned with selling the vision of a technology-driven and technology-based future. Technology would fix many of the world's problems, including hunger, disease, scarcity, and war. That 45 million people attended this fair indicated how much the instrumental (and enthusiastic) view of technology had captured the feelings of a larger part of the American people.

\section{The Coming of Reflexive Modernization}

Although World War II showed again that death could be efficiently mass produced by technology, technological enthusiasm prevailed for at least two decades after 1945, in Europe as well as in the United States. These were the decades of Big Science, and after two decades of hardship during depression and war, consumer society finally became a reality for all, including labor and Europe. Science and technology were seen as the key to American prosperity, the rebuilding of Europe, and the future of the world. In the 1960s, however, people began to find, somewhat to their surprise, that new products can have serious problems, so-called unintended consequences. Various citizens' groups, nongovernment organizations (NGOs), and intellectuals, such as Commoner, Ellul, Mumford, Nader, Marcuse, and Roszak, started to challenge the promise that science and technology could solve any problem (see, for example, Nelkin 1979; Hughes 1989: chap. 9; Eyerman and Jamison 1991; Bauer 1995).

Overt resistance against new technologies, especially nuclear energy, flourished, effectively frustrating its further development in the 1970s. New social movements reversed modernism's trust in technology by 
issuing critical calls for values such as quality of life, wholeness, smallness, care for nature, and concern for future generations. The attempts by governments and companies to improve "public understanding" were seen as defensive and self-serving. This distrust was not only fueled by accidents and other impacts of technology that became visible, but also by a critique of centralized large-scale technologies. The various controversies and disputes were not merely about the impacts themselves, but also were about wider social and moral preferences and values (see Irwin 1995; Irwin and Wynne 1996).

Not only was resistance against new technologies reinvented, the idea of developing alternative systems and technologies consonant with the new value system became popular. In 1973 E. F. Schumacher published Small Is Beautiful: Economics As if People Matter, in which he advocated a latter-day "intermediate technology." In 1977 appropriate technology in the United States received official sanction in a new National Center for Appropriate Technology. The Army Corps of Engineers was ordered to identify dams that might be retrofitted to low-head hydroelectric production. Many programs for research and development on renewable energy were set up (Pursell 1995: chap. 13, 1993). Particularly in Denmark, small-scale wind energy was developed and used successfully (Jørgensen and Karnøe 1995). Many examples of socalled clean technologies emerged during these years (Green and Irwin 1996).

In addition to the development of more appropriate and cleaner technologies, western societies since the 1970s have witnessed an explosion of new governmental regulations as well as a huge increase in knowledge about environmental problems and solutions. The consequences of new technologies have been increasingly assessed, monitored, and regulated. Also, these consequences (dangers, risks, impacts) began to dominate public and political debates. For this reason Ulrich Beck has argued that we have entered a new phase in the modernization process, a phase of reflexive modernization in which industrial society confronts its own problems (Beck 1992, 1994). Thus "reflexive" does not refer merely to reflection, but foremost to self-confrontation.

Still, although western societies seem to recognize their problems, a solution to them is not at hand. Alternative technologies, such as wind 
energy, organic farming, and electric vehicles occupy only small market niches, while many "clean" technologies, from the chimney filter to the catalytic converter, do not solve the problem, but only displace it and create new problems elsewhere. Regulation is often not very effective, while the promotion of new, risky technologies such as genetic engineering continues, and many problematic old technologies such as gasolinefueled automobiles flourish. No clear picture has emerged on how to effectively handle even widely recognized problems. This leads for some to an uneasiness; for example, people still drive automobiles but feel a bit guilty about it. For others, the intractability of these problems leads to apathy and indifference.

The case of the expansion of the Amsterdam Schiphol Airport serves here to illustrate the strains of reflexive modernization and the persistence and limitations of modernist technology politics. In this case the dual-track approach of separating promotion and regulation was clearly articulated and codified in official policy, even as the defects of this policy became clear to many parties involved.

In 1969 the director of Schiphol Airport made a plea for a large expansion of the airport, particularly the construction of a fifth runway. ${ }^{13}$ A long battle ensued between the national government, the provincial government, and various local municipalities, against a background of organized resistance by a variety of local communities and environmental groups. During this battle, the number of flights at Schiphol increased dramatically and the airport itself was expanded, but permission to build a new runaway was repeatedly delayed until February 1995. In these years, many studies-including a so-called integral environmental impact statement-were done to explore, determine, and calculate all the impacts. The national government's decision to allow the construction of a fifth runway was part of a broader policy for the airport. According to this policy, Schiphol would be allowed to grow, albeit within certain limits set by noise standards. The number of residences to be affected by serious noise pollution was set at a maximum of ten thousand. This policy was labeled a "dual decision," and defended as a policy that would achieve competing economic and environmental goals.

This "dual decision" was developed by a project group that included the airport managers, municipal administrators, and various national 
ministries, who arrived at that consensus before commencement of the formal decision-making procedures, including a public inquiry. Consequently, citizens' groups and various NGOs distrusted the ensuing process of public participation from the start. The "dual decision" has dominated the political debate since 1995. Discussions range from such issues as how to measure noise effects to which types of runway configuration would allow steady growth with the least noise. Resistance also continued, as citizens and NGOs tried to slow down the process of building a fifth runway. These efforts have met with some successes; namely, court appeals and other actions such as the refusal to sell land needed for the expansion of the airport (which was preemptively bought up by activists before the airport started to buy the needed land).

The drive to expand the airport cannot be understood merely in terms of a growing need for air travel. The expansion of Schiphol is a part of the story of the Netherlands as "the Gateway to Europe," distributing goods and people. This story is particularly forceful in the Dutch context because it reconnects the present to the Golden Age of the seventeenth century, when Holland and especially Amsterdam was the hub of international trade. In this storyline, resistance to growth and a growing transport sector is viewed as resistance to progress, a sound economy, and to a core cause of Dutch prosperity.

In the debates since the end of the 1960s, environmental groups and local communities have hammered home the adverse environmental effects of expansion and trivialized the appeal to national economic interest. These critics pointed at airplanes contributing to the greenhouse effect, overuse of space, noise production, congestion of automobiles around the airport, and safety problems. (In 1992 an airplane crashed into an Amsterdam neighborhood, killing 47 people.) They called for stricter norms and limits to growth. At the same time, they attempted to develop alternatives. For example, they proposed a much smaller airport that would not accommodate so many transit passengers flying to the rest of Europe (such transit passengers, it was argued, contribute little added value to the Netherlands). A fierce debate among economists has persisted over the calculations of the added value of the airport expansion. NGOs developed the idea of a "railport," whereby passengers bound for Frankfurt, Paris, and other European cities would be forced 
to continue travel by rail. They also hinted at options for integrating air transport into a broader, multimodal transport policy.

Other critics argued that the only way out is not to start with technology. Real solutions will only come from social and cultural change, to be enforced through regulation. The way forward, in this view, is through restricting mobility (through price mechanisms that make jet fuel much more expensive, creating a new tax on flying, or enforcing mobility quotas). The management of Schiphol Airport hardly responded to these ideas, other than by pointing at the growth in the number of flights and the competition among European airports, forcing Schiphol to grow as fast as possible. At the same time, airport planners did incorporate a train station in the construction plans for an expanded airport. Also, a number of successful measures were taken to reduce the airport's energy use.

In the prolonged Schiphol controversy, economic growth was discussed simultaneously with risk production and risk distribution. Risks were made visible, and attempts were made to measure and predict them; this is a key element of reflexive modernization. Also, the two tracks of promotion and regulation-identified in this essay as the modernist way of handling technology in society-were explicitly labeled in the "dual decision" governmental policy. However, the attempts to integrate the risks into a policy did not lead to a viable solution that was acceptable to the range of actors. This suggests limits to the modernist technology politics. How can we explain this lack of room for negotiating a solution?

The Schiphol case is an exemplar for many other "risk issues" (BSE [so-called mad cow disease], food toxins, nuclear threats, global warming). The failure to resolve these issues, it seems, deepens the distrust and alienation experienced by many citizens. Following my analysis of the rise of a modernistic technology politics, we can see two phenomena at play. First, no space or arena for collaboration, discussion, and mediation on how to deal with the impacts of technology was available. ${ }^{14}$ Second, no discourse was readily available to the participants so they could understand the relationships between technology choice and technology impact. A feeling of shared responsibility between producers of new systems and those who use or are affected by them cannot emerge 
in such a situation. Typically, only those acting to promote it have any access to decision making about a future technology, system development, and the attendant impacts, leaving ample room for viewing promoters as the "bad guys" seeking only profit.

In the Schiphol case, public participation, which is often held out as a robust solution to such conflicts, did not result in any substantial access or choice of technology. The national government tried several times to create a "roundtable" to discuss the future of the airport with varied actors, but these attempts failed because of the airport's low institutional credibility and the lack of common ground for discussion. The airport management continued to perceive a binary choice-Schiphol could remain a regional airport or it could become a huge international one, which would require a fifth runway. Opponents of the airport expansion viewed airport growth and the construction of a fifth runway as the problem. For them, system growth needed to be curtailed through strict regulation that might change the travel patterns of passengers.

Solutions to the Schiphol impasse were thus sought in either a "technology" fix or a "regulation" fix. As I have argued, both approaches are deeply embedded in our culture and dominate the debate about many technological systems. The key issue my analysis raises is whether modern societies are indeed trapped within these two conflicting positions. Would it be possible to conceive of a modern culture able to discuss contending social and cultural issues in relation to technology? This leads to the related question of what conditions would encourage and allow actors to work on both the technical and the social simultaneously, in a related way.

\section{Contours of a Constructive Technology Politics}

The core of modernist technology politics, as I have argued, lies in the separation of technology from its social effects. The separation emerged in the early modern period and was a defining characteristic of modernity. I have interpreted resistance by the Luddites in the eighteenth and nineteenth centuries as resistance to that separation. They demanded that those who introduced new technology anticipate its social effects. To the Luddites and their sympathizers, technology did not inhabit a 
realm separate from its social, cultural, and political effects. This was also the case for a larger part of the Rotterdam dockworkers at the turn of the twentieth century. The socialist leaders and other members of the elite, however, viewed technological developments as unavoidable and could not perceive viable alternatives. Environmental groups and other protesters against the prospective expansion of Schiphol were more ambivalent. By attempting to formulate alternatives, they did not define the contemporary plans for Schiphol's expansion as unavoidable. But their efforts were hampered by the absence of a language and space to create alternative designs for Schiphol.

These social, cultural, and institutional liabilities make it clear why, under the modernist regime, the technical is kept separate from the political. No wonder that it is so difficult to develop a new relationship between technology and the political realm. In this last section of my chapter, I develop some ideas about how to overcome the bias of modernist technology politics that separates the technical and the social. In doing so, my tone will become less descriptive (aiming at diagnosis) and more prescriptive. Indeed, I aim to prepare intellectual ground for a new kind of modernist technology politics, one that could be called "constructive technology politics." 15

To achieve such a constructive technology politics, it will be necessary to nurture a new set of institutions and discourses that aim at broadening the design of new technologies to include societal actors and factors. When such institutions proliferate, design processes will happen in new networks and circumstances. Ultimately such a development would allow for the constructive experimentation of technology and society. ${ }^{16}$ It is not constructive in the sense of avoiding conflict. Power games will still be played; however, these will be partly displaced to other arenas, and here affected persons and institutions will be in a position to take responsibility for the construction of technology and its effects. By institutionalizing negotiation spaces (or nexus), both proponents and opponents will become responsible for giving meaning to technology and its effects.

The view that design processes must be broadened is not based on any presumption that social effects play no role in present design processes. On the contrary, they are present in the form of (sometimes implicit) 
assumptions about the world in which the product will function (Akrich 1992, 1995). The effect of broadening is that the designers' assumptions or "scripts" concerning their technologies ${ }^{17}$ are articulated as early as possible to the users, governments, and other parties who will feel the effects of the technology, and have their own scripts. At present, there is no space for such an early exchange of contending scripts.

If the design process is broadened, it could acquire three beneficial features: anticipation, reflexivity, and symmetrical social learning. ${ }^{18}$ In the first feature, actors would organize the anticipated impacts on a continuous basis. Through reflexivity ${ }^{19}$ they would have the ability to consider technology design and social design as an integrated process and to act upon that premise. Finally, through symmetrical social learning, the actors would learn about all aspects of a new technology simultaneously. The vision is of new technologies evolving through a mutual learning process: technological options, user preferences, and necessary institutional changes are not given ex ante, but are created and modified along the way. Many historical and sociological studies have shown how user demands and regulatory requirements are articulated and expressed during the development process itself, in interaction with the technological options (Clark 1985; Green 1992). Producers gain new perspectives on their technologies from their customers and in response modify their designs.

In current design processes, mutual learning rarely takes place because of a prevailing tendency to optimize technology first, then check for user acceptance, and finally examine regulatory fit. Of course, no design process is strictly linear, and most design schemes include planned feedback. Feedback also arrives unexpectedly as problems discovered during application force redesign. However, such adjustments rarely change the pervasive assumption that design and development have to focus first on optimizing a technology before specifying markets and detailing social effects.

Incorporating reflexivity, symmetrical learning, and anticipation in design is not directed at substantive goals such as the reduction of environmental pollution or the creation of more privacy. It does not even lead to an argument about the desirability of such goals. The purpose of incorporating these features in design processes should be to shape 
technological development processes in such a way that social and technical aspects are symmetrically considered. However, it can be argued that when design processes assume these features, fewer undesired (and more desired) effects will result. By incorporating anticipation, reflexivity, and social learning, technology development becomes more transparent and more responsive to the wishes of various social actors. They will address the social effects that are relevant to them. Furthermore, in a society where these new development processes have become the norm, technology developers and those likely to be affected by the technology will be in a position to negotiate about the technology. An ability to formulate sociotechnical critique and contribute to design will become widespread. Resistance to specific social aspects will not be viewed as "technophobia," but as an opportunity to optimize the design to achieve a better fit in society.

The effect of breaking away from modernist management patterns will not be to bring technology "under control" so that it plays a less dominant role in society. Technology is not out of control. What will change is the form of control and how technology development is played out. The goal is to anticipate effects earlier and more frequently, to set up design processes to stimulate reflexivity and learning, and thus to create greater scope for experimentation. Winner (1977) asked for more space for experimentation. His concrete proposals are a bit disappointing, however; they consist of negative experimentation, that is, not using a number of technologies. My proposal is for constructive experimentation. Technologies need to be nurtured, but in a design process that allows various actors to become engaged (see Smits 1997). ${ }^{20}$

Eventually this change will make technologies more open and more flexible so users can easily control them. Technological development will also become more complex. The variety of technological designs probably will increase, for more groups will be addressed in their capacity as knowledge producer and technology developer (Verheul and Vergragt 1995). More coordination and new competencies will be required. In some cases technical change processes will slow down. New institutions will emerge to encourage negotiation among developers, users, and third parties. Should design processes acquire the features of learning, anticipation, and reflexivity, technologists will not suddenly 
see their work disappear or have it constantly evaluated by all sorts of commissions. Most of the incremental design changes will not require special negotiation at all, since social aspects will be included on a routine basis. They will be part of the technological "regimes" that orient design and use (Rip 1995; Rip and Kemp 1998).

My call for new design practices extends beyond changing and/or improving the design processes surrounding individual technologies. The point is ultimately to change the way design is done in our modern society. This change does not imply that the design activity itself needs to be put up for discussion. Modern society-a society where there is room to innovate and to create stable artifacts and networks-is accepted. Only the design process is the object of change. To make that change, inspiration can be sought in early Romantic thought, in which technology and society are not pulled apart and in which individual autonomy and the relevance of different rationalities held by different groups is accepted and used as a resource (Blechmann 1999; Schwarz and Thompson 1990). The design process must make way for confrontation, power struggles, ideological criticism, and the exchange of various rationalities. Only then will anticipation, reflexivity, and social learning be well served.

\section{Notes}

1. I would like to thank Mikael Hård for his comments on an earlier version of this paper and Tom Misa for his suggestions on revisions.

2. In recent philosophy of technology, it is common to make a distinction between instrumental and substantive positions; both result, however, in an analysis that emphasizes that technical change is ruled by itself, that is, by norms of efficiency and gradual and linear improvements to better systems (see Feenberg 1999a and Achterhuis et al. 1997.)

3. My technology-policy activities include working as an analyst for the Netherlands Organisation for Applied Scientific Research - Centre for Technology and Policy Studies (TNO-STB), many consulting jobs for government agencies and NGOs, as well as founding (along with Kurt Fischer in 1991) and participating in the Greening of Industry network <www.greeningofindustry.org $>$.

4. The workers later were given the name "Luddites" after their legendary leader Ned Ludd, who signed messages in the name of the workers. My interpretation of the Luddites was first formulated in my thesis (Schot 1991). Recently, a similar argument has been put forward by Nuvolari (1997). His paper has helped me sharpen my arguments and views. 
5. See Nuvolari (1999), who cites R. L. Hills, "Hargreaves, Arkwright and Crompton: Why Three Innovators?" Textile History 10 (1979) 114-126; compare Berg (1985: pp. 236-239, 243).

6. Nuvolari (1999: p. 7) cites Randall (1991: pp. 82-83) and Rule (1986: p. 365) for the woolen case and the seminal work of Hobsbawm and Rude (1969) on the Swing riot, Captain Swing.

7. See, for example, Rosenband (2000: p. 50): "Put another way, the state technicians' and the entrepreneurs' search for unfettered space, in which they could manipulate technique freely, placed them on a collision course with the workers' custom and the skills that undergirded it."

8. Alder (1997: p. 302) even calls the decision to become neutral "the ur-event in the relations between science and politics in the modern era. As many historians have noted, science as a profession and politics as a public activity both came of age in France at the end of the eighteenth century. Yet after a brief period of intense involvement, scientists (with very few exceptions) have generally shied away from formal party politics."

9. Notwithstanding the emerging consensus on an instrumental vision of technical change, various countries, regions, and industrial sectors did not follow an identical industrialization path; industrialization was a varied and complicated experience. In Britain and elsewhere craft production was highly innovative and contributed to economic growth (Berg 1985). France followed a specific route toward industrialization that was based more on skilled flexible small-scale industries producing a varied assortment of goods for large but constantly shifting markets. This other route was thus a result of technology choices (see Sabel and Zeitlin 1985; Mokyr 1990: pp. 113-148, 256-261). The same thing happened in the Netherlands, where in a number of industries small-scale solutions were preferred above mass-production technology. The Netherlands followed its own distinct path too, mixing craft and mass production in a Dutch blend (Schot 1995, 1998). For the United States, typically cited as the Mecca of mass production, Phil Scranton (1997) has emphasized the importance of smaller and medium-scale enterprises (over mass-production formats).

10. For sources on the elevator controversy, see van Lente (1998a,b) and van Driel and de Goey (2000, pp. 38-42).

11. Examples of such choices were elevators that would permit trade in sacks of grain instead of large "bulk" grain loads; smaller elevators that allowed slower discharge; elevators that allowed manual instead of automatic weighing. In addition, combinations of an elevator regime and a manual transshipment regime were conceivable.

12. The notion of the need to regulate technology, albeit in a different way, is also visible in the work of a number of philosophers who developed a substantivist critique of technology: Adorno, Horkheimer, and Habermas. They do not question the instrumental definition of technology, but only want to limit its application. 
13. For a detailed history of the Schiphol expansion, see Schot (1995) and Bouwens and Dierikx (1996).

14. Such mediation forums are available for integrating constructed user needs into design (see Schot and de la Bruhèze, forthcoming.)

15. In other publications, this kind of politics of technology is labeled "constructive technology assessment" (Rip et al. 1995; Schot and Rip 1998).

16. See Weber et al. (1999) and Hoogma et al. (2002) for ideas on how to design constructive experiments.

17. I use a broad definition of designers, namely, technicians, managers, and workers who are directly involved in the design process. In this respect Staudenmaier (1989) has termed it a "design constituency."

18. Note that these three features can also be transformed into management criteria; that is, particular agencies could use them proactively in assessing and upgrading design processes. For a elaboration of these criteria, see Schot (2001).

19. My notion of reflexivity is very different from the one used by Beck.

20. Such constructive experimentation is a form of neo-Luddism, but the nature of this action is quite different from that implied in its use by a number of other authors. Kirkpatrick Sale (1995) invites individuals to scrutinize any new technology for possible harm and if needed, reject it. No proposals are made to change the nature of the design process itself. It is my conviction that this is precisely what the Luddites were after, while individual technologies per se were not their main concern. 